\title{
Comparing asphalt modified with recycled plastic polymers to conventional polymer modified asphalt
}

\author{
G. White \& F. Hall \\ School of Science and Engineering, University of the Sunshine Coast, Sippy Downs, Queensland, Australia
}

\begin{abstract}
As sustainable infrastructure solutions become a focus of societies and governments, the interest in recycling plastic into asphalt mixtures will continue to increase. There are many forms of plastic that can be added to asphalt, but those plastics that partially replace the bituminous binders, as well as improve the mechanical properties of the asphalt mixture, are the most valuable. The effects of $6 \%$ (of bitumen mass) of two commercially available recycled plastic products were compared to the effects of $2-6 \%$ conventional elastomeric and plastomeric polymers, within a typical dense graded asphalt mixture. The Marshall stability associated with recycled plastic was comparable to that for $2-3 \%$ conventional polymer content, while indirect tensile stiffness and deformation resistance were comparable to $4-6 \%$ conventional polymer content. In contrast, workability, Marshall flow and moisture damage resistance were not significantly different for recycled plastic and conventional polymers, regardless of the conventional polymer content. It was concluded that the recycled plastic products used in this research should be thought of as sustainable polymers for asphalt mixture modification, rather than as simple extenders of the bituminous phase in asphalt production. However, further work is required to understand the ageing, leaching and fuming of asphalt mixtures modified with recycled plastic, compared to conventional polymers.
\end{abstract}

Keywords: Asphalt, Modification, Waste, Recycled, Plastic, Polymer

\section{INTRODUCTION}

The desire to develop sustainable infrastructure, including pavement structures and materials, is ever increasing in recent times (NAPA 2020). Given the diversity of pavement structures, which can include cement concrete, asphalt mixtures, granular crushed rock and natural gravels, the opportunities for sustainable pavement construction are broad and many. When considering sustainability opportunities, it is important to take into account the effect on the durability and expected life of the pavement, as well as the reduction in financial or environmental cost of the more sustainable solution (Jamshidi \& White 2019). That is, an initiative that reduces the new pavement's greenhouse gas emissions by $20 \%$ is not really sustainable if the pavement only lasts $50 \%$ of the life of the conventional solution (Jamshidi \& White 2020). It is also important to understand that sustainability initiatives are only viable if the cost to collect, process and reincorporate a recycled material or product is less expensive than the cost of the material or product that it replaces (White 2019). For this reason, the replacement of high cost materials, such as bituminous binder and cement, with recycled or repurposed materials, is of great interest to practitioners and researchers alike.

One opportunity is to replace high cost bituminous binder with low cost recycled plastic in asphalt mixtures (NAPA 2020). However, there are many types and forms of recycled plastic

DOI: $10.1201 / 9781003222880-1$ 
and only a few of them are well suited to recycling in asphalt mixtures (Brasileiro et al. 2019; Masad et al. 2020). Some binders and asphalt mixtures modified with recycled plastic have been reported to have properties comparable to those generally associated with conventional polymer modification (White \& Reid 2020). Consequently, some researchers have recommended a direct comparison to polymer modified binders (PMB) and asphalt mixtures produced with PMB.

This research compares the effects of two commercially available recycled plastic products, to the effects associated with asphalt mixtures modified with the conventional polymers styrene-butadiene-styrene (SBS) and ethyl vinyl acetate (EVA). The aim was to determine the dosage of conventional polymers that gave comparable asphalt performance property values to those associated with the recycled plastics. Common performance-indicating tests were undertaken on otherwise identical asphalt mixtures produced with bituminous binder modified with varying dosages of various conventional polymers and two recycled plastic products.

\section{BACKGROUND}

\subsection{Approaches to recycling plastic in asphalt mixtures}

As stated above, there are many approaches to recycled plastic in asphalt mixtures. The polymer and form of plastic, the aim of the user and the local logistics all influence the most appropriate approach to make. However, these same factors will also affect the properties of the resulting asphalt mixture and the long-term performance of the road surface. In general, there are four approaches to recycling plastic in asphalt mixtures (White 2020):

- Uncontrolled waste disposal. Uncontrolled incorporation of variable plastics with only minimal processing to reduce the particle size to be comparable to asphalt mixture aggregates. This offers minimal return on the investment and a higher performance risk.

- Aggregate extension. Hard plastic does not melt at typical asphalt production temperatures, but can partially replace or extend the aggregate in the mixture. However, the aggregate is much less expensive than the bituminous binder, so this approach provides a lower return on the investment. Some performance enhancement is often reported due to the reinforcing nature of the plastic, which is often flexible in nature.

- Binder extension. Soft plastics can melt into the bituminous binder to partially replace or extend the binder without necessarily enhancing its properties. This provides a greater return on the investment than aggregate extension, because the binder is significantly more expensive than the aggregate.

- Binder extension and modification. When soft plastic is used to modify, as well as extend, the bituminous binder, the effects can be similar to those associated with traditional polymers for binder and mixture modification.

The use of plastics that can both modify and extend the bituminous binder is the most beneficial approach to recycling plastic is asphalt mixtures. This is because the extended bituminous binder is expensive, but the polymers that would otherwise be used for asphalt mixture performance enhancement are even more expensive.

\subsection{Use of plastic in asphalt on roads}

Many countries have now reported the use of recycled plastic in asphalt mixture production, either as an aggregate extender, a bitumen extender or a binder modifier. For example, Vancouver (Canada) incorporated plastic crate waste as a warm mixed asphalt wax additive in 2012 (Ridden 2012) and Rotterdam (Netherlands) announced a plan to produce recycled plastic segments in a factory for road construction in 2015 (Sani 2015). Also, Jamshedpur (India) reported reducing bitumen usage by $7 \%$ by mixing shredded recycled plastic during asphalt production (PTI 2015). More recently, a New Zealand asphalt contractor added shredded engine oil containers to asphalt at Christchurch Airport (Parkes 2018) and an independent 
asphalt producer includes recycled plastic as a bitumen extender in every tonne of asphalt produced. South Africa commenced recycled plastic trials in 2019, on a road near Jeffrey's Bay (BusinessTech 2019).

In Australia a comparative trial of three recycled plastic extenders and modifiers was constructed in May 2018, which was shortly followed by other trials in Melbourne (IPWEA 2018), Sydney (Tapsfield 2018), Adelaide (Pisani 2018) and Canberra (Roberts 2019). Previous use of recycled plastic in the United Kingdom has recently been expanded to include roads and highways from Cumbria in the north, to Kent in the South, and many counties in between (Doyle 2019). Even the United States has now performed trials in San Diego (Grifin 2018) and more recently in downtown Los Angeles (Houser 2019) as well as a highway near Sacramento (Bousquin 2020).

Many of these trials have simply surfaced or resurfaced pavements with asphalt containing recycled plastic. Some have complimented construction trials with laboratory testing and evaluation of the mixtures. Furthermore, some trials have included otherwise identical asphalt mixtures, but without recycled plastic, to allow side-by-side comparison in the same mixture, in the same environment and subject to the same traffic loading. The side-by-side investigations that included laboratory investigations are particularly useful because they allow the effect of recycled plastic on asphalt mixtures to be objectively measured.

\subsection{Effects of recycled plastic on asphalt mixtures}

There are hundreds of recycled plastic polymers available for use in asphalt mixtures. However, to be practically recycled in asphalt mixtures, a plastic must melt at typical binder blending and asphalt production temperatures, which are typically limited to a maximum of $185^{\circ} \mathrm{C}$. They must also be available in appropriate quantities and in a form that makes cleaning and pre-processing economically viable. Furthermore, because reuse as a new plastic product is preferred over recycling into construction materials, selected plastics should be otherwise destined for landfill. When these constraints are considered, polyethylene, polypropylene, polyvinyl chloride and ethyl vinyl acetate become the most viable plastics for recycling in asphalt mixtures (Brasileiro et al. 2019). Because of its high melting point, polyethylene terephthalate, which is commonly known as PET and is abundantly available in the form of plastic drink bottles, is not actually viable (White \& Reid 2019). Researchers have concluded that polyethylene is the most viable type of plastic to be recycled as an asphalt mixture modifier (Brasileiro et al. 2019). As a result, many researchers have focused on evaluating the effect of recycled polyethylene in bituminous binder and asphalt mixtures.

Dalhat \& Wahhub (2017) shredded and ground low and high density polyethylene, as well as polypropylene, and wet mixed the recycled plastic products into bitumen prior to asphalt manufacture in the laboratory. The viscosity of the binder increased, as did the Performance Grading (PG) of high temperature rating. The asphalt modulus increased and when a typical asphalt pavement was modelled in a pavement management model, the predicted rut depth and top-down longitudinal cracking were both predicted to reduce significantly (Dalhat \& Wahhub 2017).

Yin et al. (2020) modified binders and mixtures with 2-3\% polyethylene, with and without reactive elastomeric terpolymers to improve storage stability. It was concluded that polyethylene modified mixtures had better deformation resistance and increased stiffness, but reduced moisture damage resistance. It was also concluded that low temperature fracture, intermediate temperature fatigue, block cracking and reflective cracking resistance were all unaffected by the additional of polyethylene (Yin et al. 2020).

Nizamuddin et al. (2020) also assessed bituminous binder modified with polyethylene. The viscosity, softening point and penetration index all increased, and the penetration value decreased, indicating a stiffer binder. The MSCR measured elasticity and deformation resistance were also improved and it was concluded that 3-6\% was the optimal dosage, by mass of the bitumen (Nizamuddin et al. 2020). 
The products evaluated in this research are commercially available recycled plastics supplied by MacRebur (MacRebur 2020). The type of plastic is not disclosed, but one product is intended to be plastomeric in nature, while the other is intended to be elastomeric. White \& Reid (2018) previously investigated these products and found the asphalt mixture modulus increased by $120-250 \%$, wheel track rutting reduced by $0.5-1.8 \mathrm{~mm}$ and fracture toughness increased. In related work, White (2019) reported comparable moisture damage resistance and improved fatigue life of asphalt mixtures. The same products were also found to increase the MSCR-based PG of binders by three to four grades (White \& Reid 2019) and White \& Magee (2019) found similar improvements in deformation resistance and stiffness without adversely affecting the fatigue and moisture damage resistance. Most recently, it was concluded that the effects associated with these products were not significantly different when the plastic was wet-mixed into the bitumen or dry-mixed into the asphalt production plant (White \& Hall 2021). It was also concluded that the improvement in binder and mixture properties associated with the two products were comparable to those generally associated with conventional polymers for asphalt production, particularly those associated with the plastomeric EVA (White \& Hall 2020).

\subsection{The products}

As stated above, this research compared the effects of two commercially available recycled plastic products on asphalt mixture properties, to those associated with conventional polymers for binder modification and asphalt mixture production. The two products are known as MR6 and MR10 (MacRebur 2020). In 2015, MR6 was first developed to:

- Productively consume a portion of waste plastic otherwise destined for landfill.

- Reduce the cost of new road construction and maintenance.

- Increase the strength and durability of local roads.

MR6 was intended to improve deformation resistance, via an increase in asphalt mixture stiffness. MR10 was then developed to produce a more elastomeric and crack resistant bituminous binder. Both products are manufactured from $100 \%$ recycled plastic that was selected for its physical properties, as well as being otherwise not economically recyclable. That is, the plastic used to produce MR6 and MR10 would otherwise be disposed in landfill because there are no viable alternate recycling options available.

\section{METHODS, MATERIALS AND RESULTS}

Asphalt mixtures were produced with waste plastic modified binder (MR6 and MR10) and with conventional polymer modified binder (SBS and EVA), as well as unmodified penetration grade bitumen. The mixtures were otherwise nominally identical and reflected a common $10 \mathrm{~mm}$ sized dense graded and Marshall designed mixture for road surfacing in the United Kingdom. The samples were all tested for properties that are directly or indirectly related to asphalt performance, including deformation resistance, modulus, moisture damage resistance and Marshall properties.

\subsection{Materials}

As stated above, the asphalt mixture was a Marshall-designed, dense graded $10 \mathrm{~mm}$ nominal maximum aggregate sized product for local road surfacing. It is commonly used in the United Kingdom and meets the requirements of British BS EN 130108 and PD 6691 for a mixture containing basaltic coarse aggregate (Table 1). 
Table 1. Asphalt mixture properties.

\begin{tabular}{|c|c|c|c|}
\hline Property & Test method & Specification limit & Target value \\
\hline Binder content (by mass) $(\%)$ & BS EN 12697-1 & $4.5-5.5$ & 5.2 \\
\hline Voids in the aggregate $(\%)$ & BS EN 12697-8 & $18.0-22.0$ & 20.0 \\
\hline \multicolumn{4}{|c|}{ Percentage passing (\%) standard sieve size (mm) } \\
\hline Sieve size $(\mathrm{mm})$ & Test method & Specification limit (\%) & Target value \\
\hline 10 & BS EN 12697-2 & $90-100$ & 99 \\
\hline 6.3 & & $62-68$ & 68 \\
\hline 2 & & $25-33$ & 32 \\
\hline 1 & & $17-26$ & 22 \\
\hline .063 & & $4-8$ & 7 \\
\hline
\end{tabular}

Control asphalt samples were produced with 50-70 penetration-grade bitumen meeting the requirements of EN 12591. The recycled plastic modified samples all included 6\% (by mass of the unmodified bitumen) of the commercial products MR6 or MR10, shown in Figure 1. The SBS and EVA modified binders were produced with $2 \%, 4 \%$ and $6 \%$ polymer content, by mass of the unmodified bitumen.

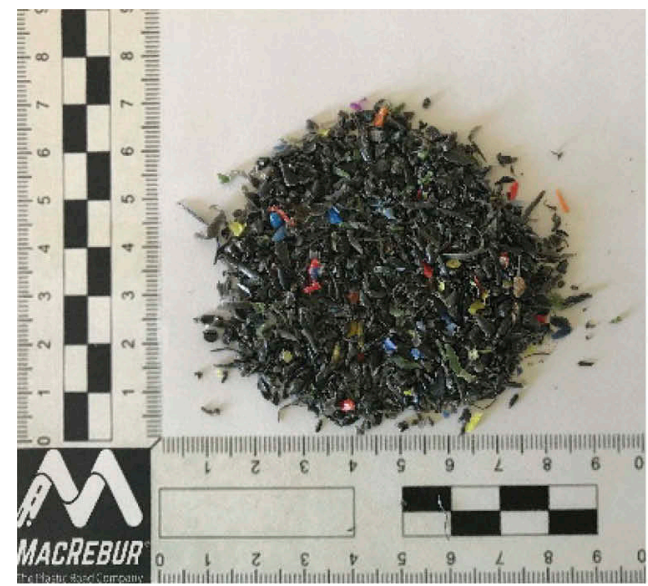

(a)

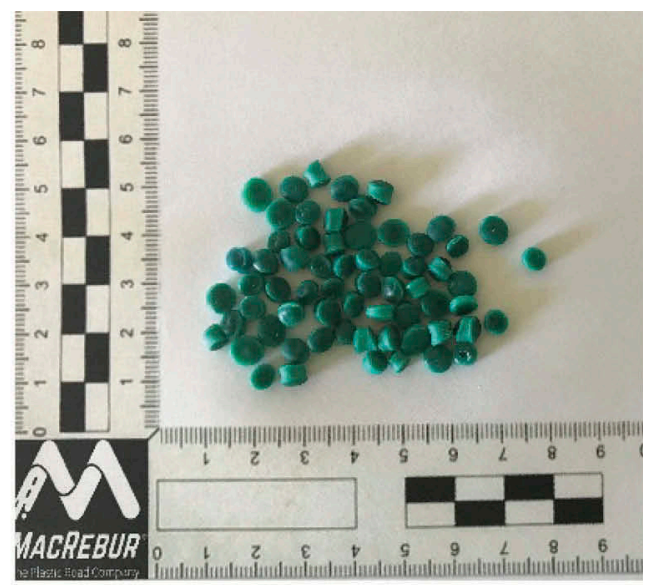

(b)

Figure 1. Current (a) MR6 shreddings and (b) MR10 pellets.

All samples were prepared in a laboratory environment. Modified binder samples were first prepared by shearing the recycled plastic or conventional polymer into the 50-70 bitumen binder for 15 minutes using a Silverson laboratory mixer. The binder was then rested at $175^{\circ} \mathrm{C}$ overnight before being mixed into the pre-graded and pre-heated aggregates at $175^{\circ} \mathrm{C}$ for 5 minutes. Test specimens were subsequently prepared and tested according to the various methods, which are detailed below.

\subsection{Methods}

Asphalt samples were generally prepared in triplicate and tested using standard United Kingdom methods, which generally reflect European Norm standards, as summarised in Table 2. The triplicate sample results allowed statistical comparisons to be made for most test methods. However, the moisture sensitivity test requires six samples, three conditioned and three not conditioned, to produce one result. Furthermore, only one bulk sample was tested for volumetric composition 
(aggregate gradation and reference density) and one wheel track result requires two test results, while as many fatigue tests as was necessary were performed to achieve a relationship between initial strain and cycles to failure, with a $\mathrm{R}^{2}$ value greater than 0.90 , for each mixture.

Table 2. Test methods.

\begin{tabular}{|c|c|c|}
\hline Property & Method & Description \\
\hline Aggregate gradation & BS EN 12697-2 & Unwashed sieve analysis after soluble binder extraction \\
\hline Binder content & BS EN 12697-1 & $\begin{array}{l}\text { Percentage of binder extracted from a bulk asphalt sample } \\
\text { after extraction }\end{array}$ \\
\hline Void characteristics & BS EN 12697-8 & $\begin{array}{l}\text { Voids in the aggregate and air voids in samples compacted } \\
\text { by a standard method }\end{array}$ \\
\hline Marshall Stability/Flow & BS EN 12697-34 & $\begin{array}{l}\text { Stability and Flow of samples prepared by } 50 \text { blows to each } \\
\text { side by a standard Marshall hammer and tested at } 60^{\circ} \mathrm{C}\end{array}$ \\
\hline Deformation resistance & BS EN 12697-22 & $\begin{array}{l}\text { Average deformation following } 10,000 \text { passes of } \\
\text { a Cooper's wheel tracking wheel at } 45^{\circ} \mathrm{C} \text { of samples com- } \\
\text { pacted using a laboratory slab compactor }\end{array}$ \\
\hline Moisture sensitivity & BS EN 12697-12 & $\begin{array}{l}\text { Ratio of indirect tensile strength of conditioned and uncon- } \\
\text { ditioned samples, where conditioning includes vacuum sat- } \\
\text { uration followed by } 72 \text { hours in a } 40^{\circ} \mathrm{C} \text { water bath }\end{array}$ \\
\hline Resistance to fatigue & BS EN 12697-24 & $\begin{array}{l}\text { Indirect tensile fatigue life of samples prepared to } 8 \% \text { air } \\
\text { voids content in a gyratory compactor, over a range of ini- } \\
\text { tial tensile strain magnitudes to allow a relationship } \\
\text { between initial strain and cycles to failure to be determined } \\
\text { with a } \mathrm{R}^{2} \text { value greater than } 90 \%\end{array}$ \\
\hline
\end{tabular}

The results were generally analysed by graphical comparison. For asphalt mixture properties measured in triplicate, Student- $t$ tests were performed for the difference of means. For all t-tests, a p-value of 0.05 or less was accepted as an indication that the difference between the two sets of results was statistically significant.

\subsection{Results}

Table 3 summarises the volumetric bulk sample test results, excluding the aggregate gradations, which are shown in Figure 2. The Marshall property and modulus results are summarised in Table 4 while the wheel tracking and TSR results are in Table 5. Some properties were also tested for the significance of the slope of a regression on the polymer content to determine the significance of the polymer content. This is noted where applicable.

Table 3. Bulk sample volumetric test results.

\begin{tabular}{lll}
\hline Mixture & Bulk density $\left(\mathrm{t} / \mathrm{m}^{3}\right)$ & Binder content $(\%)$ \\
\hline Control & 2.322 & 5.30 \\
SBS-2 & 2.353 & 5.31 \\
SBS-4 & 2.309 & 5.32 \\
SBS-6 & 2.324 & 5.31 \\
EVA-2 & 2.315 & 5.31 \\
EVA-4 & 2.301 & 5.30 \\
EVA-6 & 2.345 & 5.32 \\
MR6 & 2.298 & 5.33 \\
MR10 & 2.338 & 5.30 \\
\hline
\end{tabular}

Note: the numerical value following SBS and EVA designates the polymer content in the binder. 


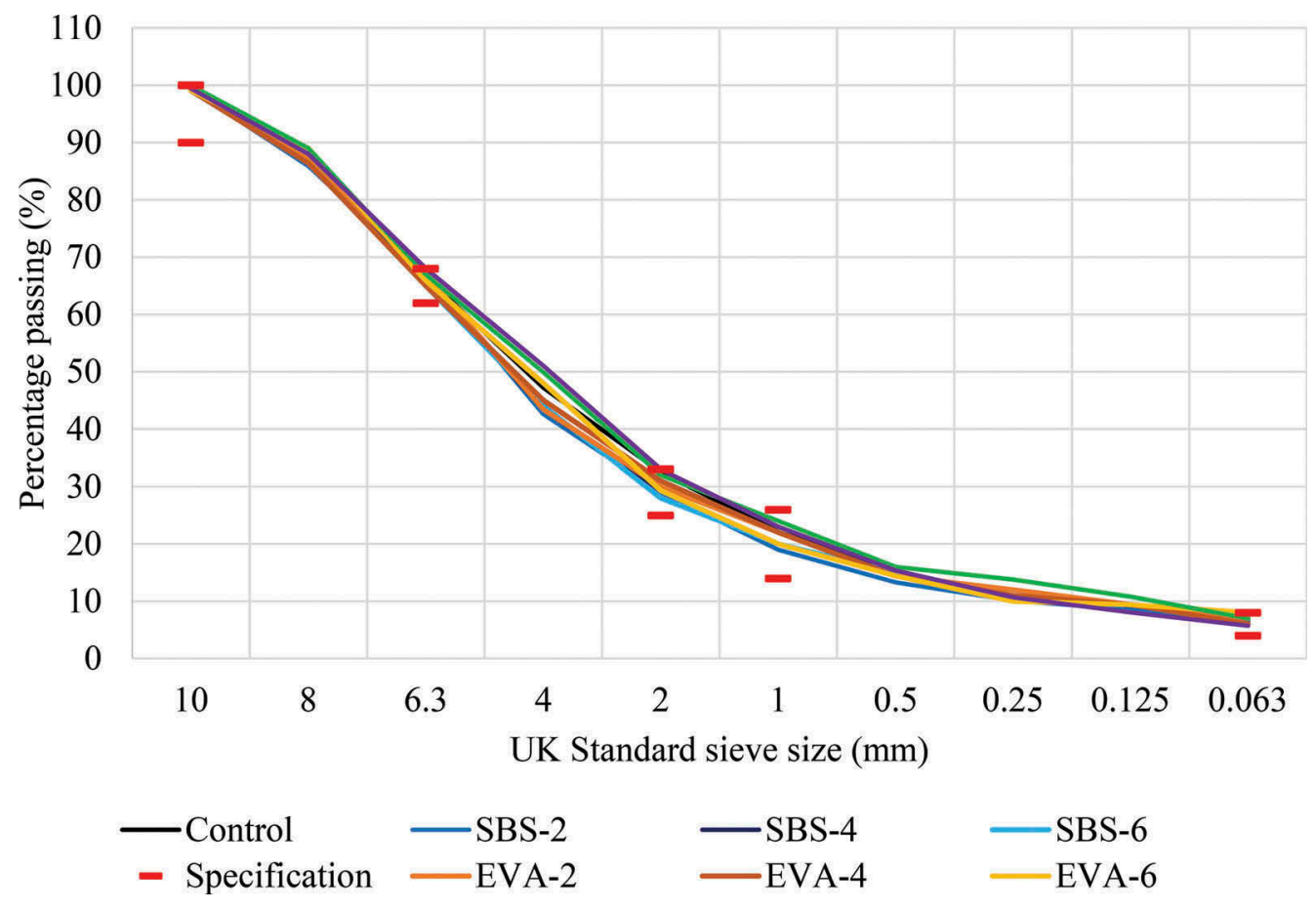

Figure 2. Aggregate gradations for various bulk mixtures.

Table 4. Sample Marshall property and modulus results (triplicate).

\begin{tabular}{|c|c|c|c|c|}
\hline Mixture & Air voids $(\%)$ & Stability $(\mathrm{kN})$ & Flow (mm) & Modulus (MPa) \\
\hline \multirow[t]{3}{*}{ Control } & 8.2 & 7.1 & 4.6 & 4,740 \\
\hline & 6.9 & 8.4 & 4.2 & 4,630 \\
\hline & 6.5 & 9.7 & 2.7 & 4,760 \\
\hline \multirow{3}{*}{ SBS-2 } & 5.4 & 8.5 & 2.9 & 5030 \\
\hline & 6.1 & 9.5 & 3.1 & 5130 \\
\hline & 6.2 & 10.0 & 3.6 & 4910 \\
\hline \multirow[t]{3}{*}{ SBS-4 } & 7.6 & 7.1 & 3.7 & 6580 \\
\hline & 7.1 & 7.3 & 2.7 & 6150 \\
\hline & 8.0 & 7.1 & 3.9 & 5220 \\
\hline \multirow[t]{3}{*}{ SBS-6 } & 6.5 & 15.0 & 2.4 & 5710 \\
\hline & 6.4 & 12.9 & 2.7 & 6570 \\
\hline & 6.7 & 13.5 & 3.5 & 6230 \\
\hline \multirow[t]{3}{*}{ EVA-2 } & 7.6 & 6.4 & 4.4 & 5030 \\
\hline & 6.4 & 7.7 & 3.8 & 5130 \\
\hline & 5.6 & 9.3 & 3.9 & 4910 \\
\hline \multirow[t]{3}{*}{ EVA-4 } & 6.5 & 10.4 & 3.1 & 7300 \\
\hline & 7.6 & 10.2 & 4.4 & 7180 \\
\hline & 7.0 & 11.7 & 3.9 & 8540 \\
\hline \multirow[t]{3}{*}{ EVA-6 } & 6.5 & 14.4 & 4.4 & 11,580 \\
\hline & 5.8 & 16.1 & 4.1 & 10,080 \\
\hline & 6.3 & 14.5 & 5.2 & 9810 \\
\hline \multirow[t]{3}{*}{ MR6 } & 7.9 & 9.8 & 3.5 & 7150 \\
\hline & 8.2 & 8.8 & 2.7 & 7330 \\
\hline & 8.3 & 4.9 & 3.5 & 7760 \\
\hline \multirow[t]{3}{*}{ MR10 } & 6.2 & 11.4 & 4.3 & 6120 \\
\hline & 7.1 & 9.3 & 5.4 & 6130 \\
\hline & 5.8 & 11.3 & 3.1 & 6600 \\
\hline
\end{tabular}


Table 5. Sample wheel tracking and TSR results.

\begin{tabular}{lll}
\hline Mixture & Rut depth $(\mathrm{mm})$ & TSR $(\%)$ \\
\hline Control & 7.1 & 82.5 \\
SBS-2 & 5.0 & 78.0 \\
SBS-4 & 3.3 & 81.1 \\
SBS-6 & 4.1 & 84.5 \\
EVA-2 & 6.9 & 88.9 \\
EVA-4 & 3.5 & 90.1 \\
EVA-6 & 4.0 & 88.0 \\
MR6 & 3.7 & 81.6 \\
MR10 & 3.5 & 81.3 \\
\hline
\end{tabular}

\section{DISCUSSIONS}

\subsection{Isolation of effects}

Before the effect of polymer content and type can be considered, it is first important to understand that the volumetric composition of the various asphalt mixtures was consistent, so that the effects of the variously modified binders is isolated from any changes in the aggregate gradation or binder content. The aggregate gradations were generally all consistent and within the specification limits, as shown in Figure 2. The binder contents and bulk densities were also consistent (Table 3) with coefficients of variation of $0.2 \%$ and $0.8 \%$, respectively, which are both well below common asphalt production variability (White \& Jamshidi 2019). As a result, it was determined that the various mixtures were produced with generally similar volumetric composition, meaning that any measured differences in the properties were generally isolated to the difference in the binder modification.

\subsection{Effect on air voids}

The air voids content of the compacted Marshall samples is an indicator of the mixture workability because the Marshall sample preparation method uses 50 blows of a standard hammer on each side of the sample, thereby imparting the same level of compactive energy to all samples. As the air void content increases, the workability of the mixture decreases. However, air voids contents are sensitive to small changes in aggregate gradation. The average air voids content of each mixture is shown in Figure 3 . The control mixture had an air voids content of $7.2 \%$. The conventional polymers were associated with variable changes, compared to the control, ranging from 5.9-7.6\%. MR 10 was associated with $6.4 \%$ air voids while MR6 was associated with $8.2 \%$ air voids. The plastomeric nature of MR6 likely reduced the workability of the mixture, but the effect was only small and may actually reflect natural variations in aggregate gradation, which affected the conventional SBS and EVA modified mixtures. This was supported by t-test p-values of the comparison to the control mixture results, which ranged from 0.10 to 0.82 for the various conventional polymers, plastics and polymer dosages. Any reduction in workability associated with recycled plastic can only be concluded as being comparable to that associated with conventional plastomeric EVA. More specific workability testing is required to form a more objective conclusion. 


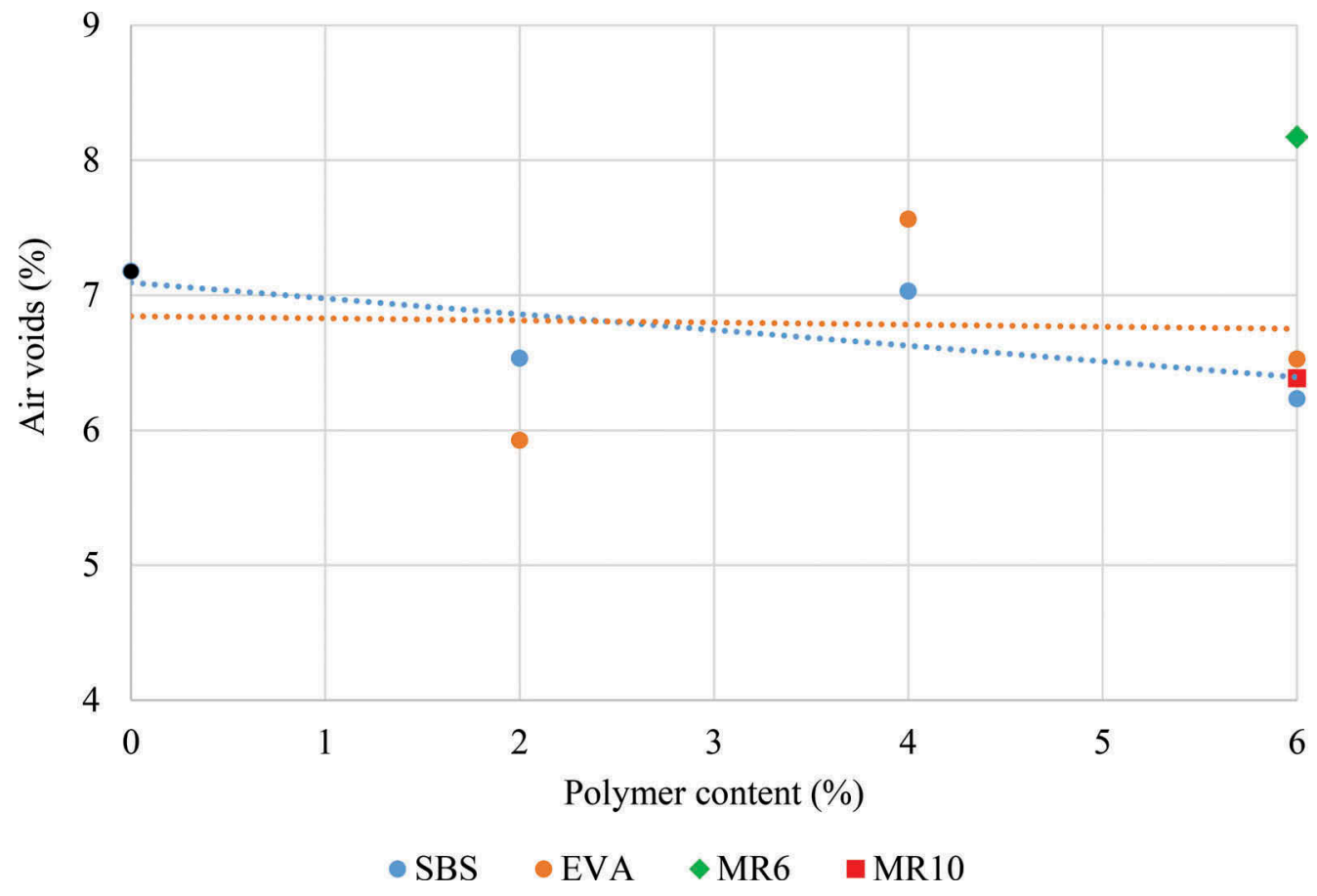

Figure 3. Asphalt mixture air voids contents after Marshall compaction.

\subsection{Effect on Marshall properties}

Marshall properties are well recognised around the world and remain useful measures of the relative contribution of the bituminous binder to asphalt mixture properties, when the mixture composition is otherwise consistent. Marshall stability is generally related to the stiffness of the binder, while the flow is generally related to the ductility or elasticity of the binder.

The Marshall stability generally increased with increasing conventional polymer content (Figure 4) with 6\% SBS and 6\% EVA associated with $64 \%$ and $78 \%$ increases in stability, respectively, compared to the unmodified asphalt mixture. These differences were significant ( $p$-values both $<0.01$ ). The increase in stability generally reflects the increased binder stiffness and the reduction in binder temperature susceptibility, which are well recognised effects of conventional polymer modification. The effects of recycled plastic were less substantial, with MR6 and MR10 associated with only $5 \%$ and $27 \%$ increases, respectively. The differences were not significant, with p-values 0.66 and 0.09, for MR6 and MR10, respectively. MR6 and MR10 were associated with results that were comparable to results associated with $2-3 \%$ of conventional polymers.

The Marshall flow generally decreased with increasing EVA polymer content, but increased with increasing SBS polymer content (Figure 5). It is likely that the decrease in flow associated with EVA conventional polymer reflects the plastomeric nature of the EVA polymer and the reduced ductility generally exhibited by plastomers. MR6 produced a similar result to 3-4\% EVA, while MR10 produced a result that was comparable to $6 \%$ SBS. This reflects the intent of MR6 to be a plastomeric modifier and the intent of MR10 to be a more elastomeric modifier. Despite these general comparisons, Marshall flow results are often associated with high variability. Consequently, none of the binders were associated with significant differences to the control mixture, with t-test p-values in the range 0.22-0.99. 


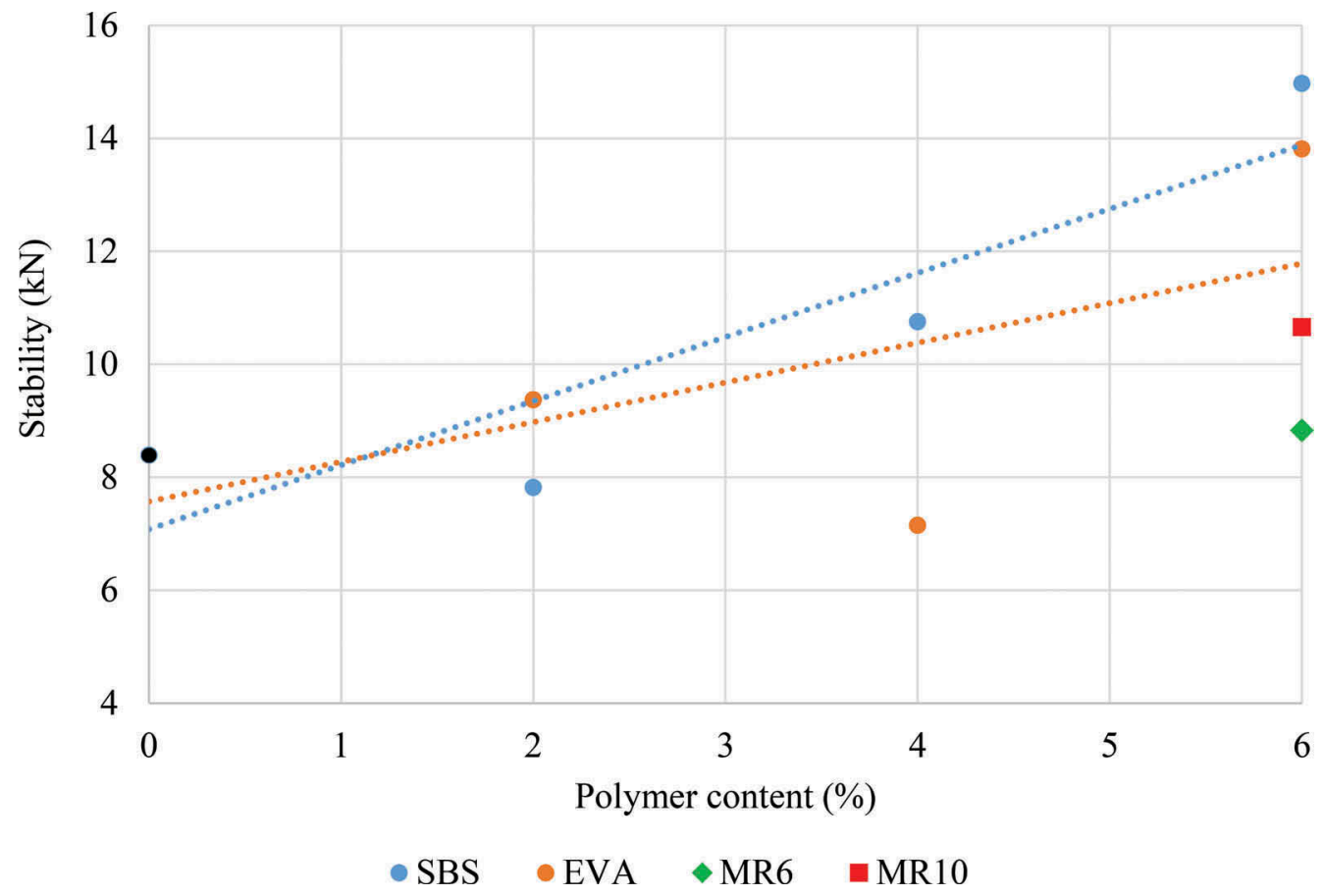

Figure 4. Asphalt mixture Marshall stability.

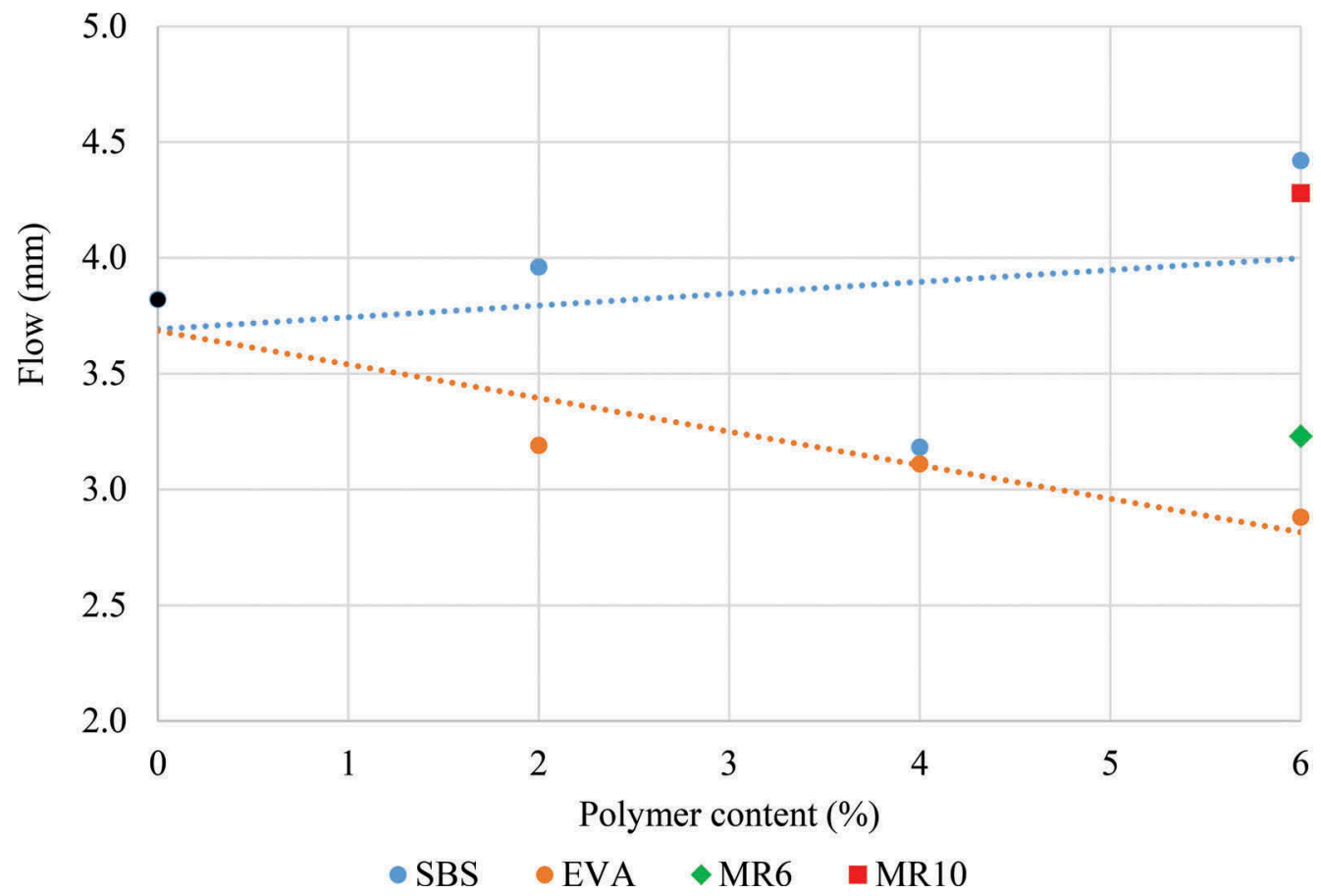

Figure 5. Asphalt mixture Marshall flow. 


\subsection{Effect on stiffness}

Stiffness is the only asphalt material property that is directly used in pavement thickness design and/or structural evaluation. Along with the Poisson's ratio, stiffness, also referred to as modulus, is used to characterise asphalt and other materials in layered elastic mechanisticempirical pavement modelling. The stiffer the asphalt mixture, the lower the pavement thickness needs to be to support the traffic loads over the design life.

Figure 6 shows the increase in modulus associated with increasing conventional polymer content. The effect of EVA polymer content was much greater than the effect of SBS polymer content, with $6 \%$ EVA producing a mixture with $123 \%$ higher ITSM than the control mixture stiffness, compared to $6 \%$ SBS, which produced a mixture with $31 \%$ higher ITSM than the control mixture stiffness. It is well established that plastomeric polymers increase asphalt mixture stiffness, while elastomeric polymers are generally associated with minor increases and occasional decreases in modulus, compared to asphalt produced with unmodified bitumen. All conventional PMB ITSM results were significantly higher than the control mixture values, with p-values ranging from $<0.01-0.03$.

Both recycled plastic products were also associated with significant increases in asphalt mixture ITSM, compared to the control mixture, with p-values $<0.01$. MR6 was associated with a $57 \%$ modulus increase, compared to $33 \%$ for MR10. This reflects the intent that MR6 be plastomeric while MR10 is intended to be more elastomeric in nature. The MR6 modulus was equivalent to that associated with approximately 4\% EVA, while the MR10 modulus value was higher than all the SBS modulus values.

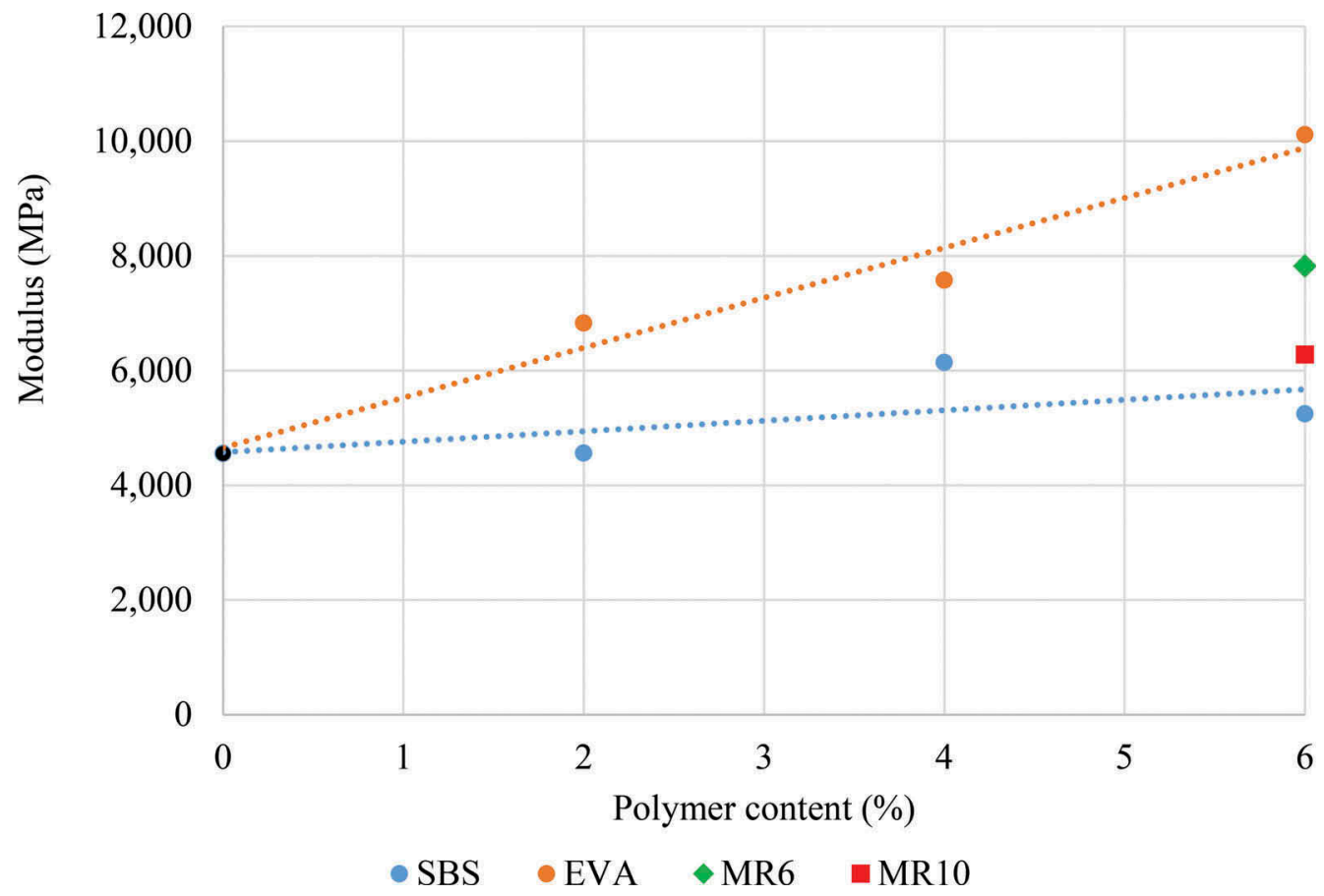

Figure 6. Asphalt mixture stiffness.

\subsection{Effect on wheel track rut depth}

Wheel track rut depth is a universally accepted indicator of deformation resistance of asphalt mixtures (Jamieson \& White 2019). Although different jurisdictions use different test machines 
and protocols, the principle of measuring the depth of a rut after cyclic loading of a small wheel in the laboratory at elevated temperature is established as a sound relative measure of deformation resistance in the field. The rut depth decreased significantly with increasing conventional polymer content (Figure 7). Both SBS and EVA were associated with a $50 \%$ reduction for $6 \%$ polymer dosage. MR6 and MR10 were associated with similar rut depth values, indicating that these products had a comparable effect to $4-6 \%$ of conventional polymer.

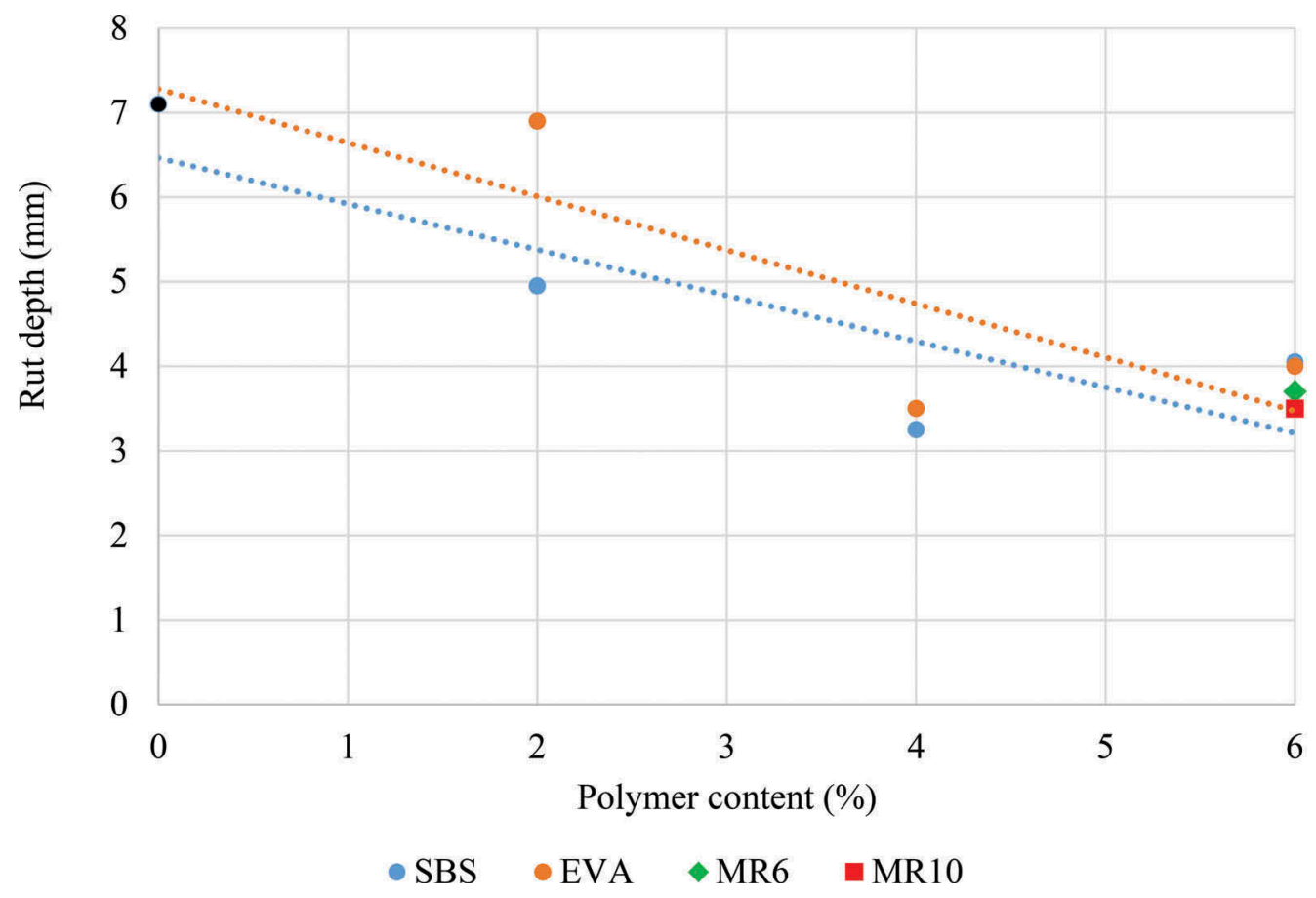

Figure 7. Asphalt mixture wheel tracking depth.

\subsection{Effect on tensile strength ratio}

All but one (2\% SBS) asphalt mixture had a TSR that exceeded the $80 \%$ value that is generally set as the lower limit for acceptable resistance to moisture damage. Because the control mixture did not have a moisture damage issue (TSR $82.5 \%$ ) the intent was not to demonstrate any improvement through binder modification. Rather, it was intended to determined whether the various polymers and recycled plastic would have any adverse effect. Overall, SBS was associated with a reduction in TSR while EVA was associated with an increase in TSR (Figure 8). However, regression equation p-values $(0.22-0.54)$ indicated that these effects were not significant. This generally reflects the variable nature of the indirect tensile strength test and the sensitivity of the TSR to small changes in sample composition, resulting in high variability and lower repeatability. Both MR6 and MR10 were associated with TSR results that were comparable to $4 \%$ SBS and slightly lower than the control mixtures. Overall, it was determined that recycled plastic had no adverse effect on the moisture damage potential of the asphalt, certainly no different to the generally variable effect of the conventional polymers. 


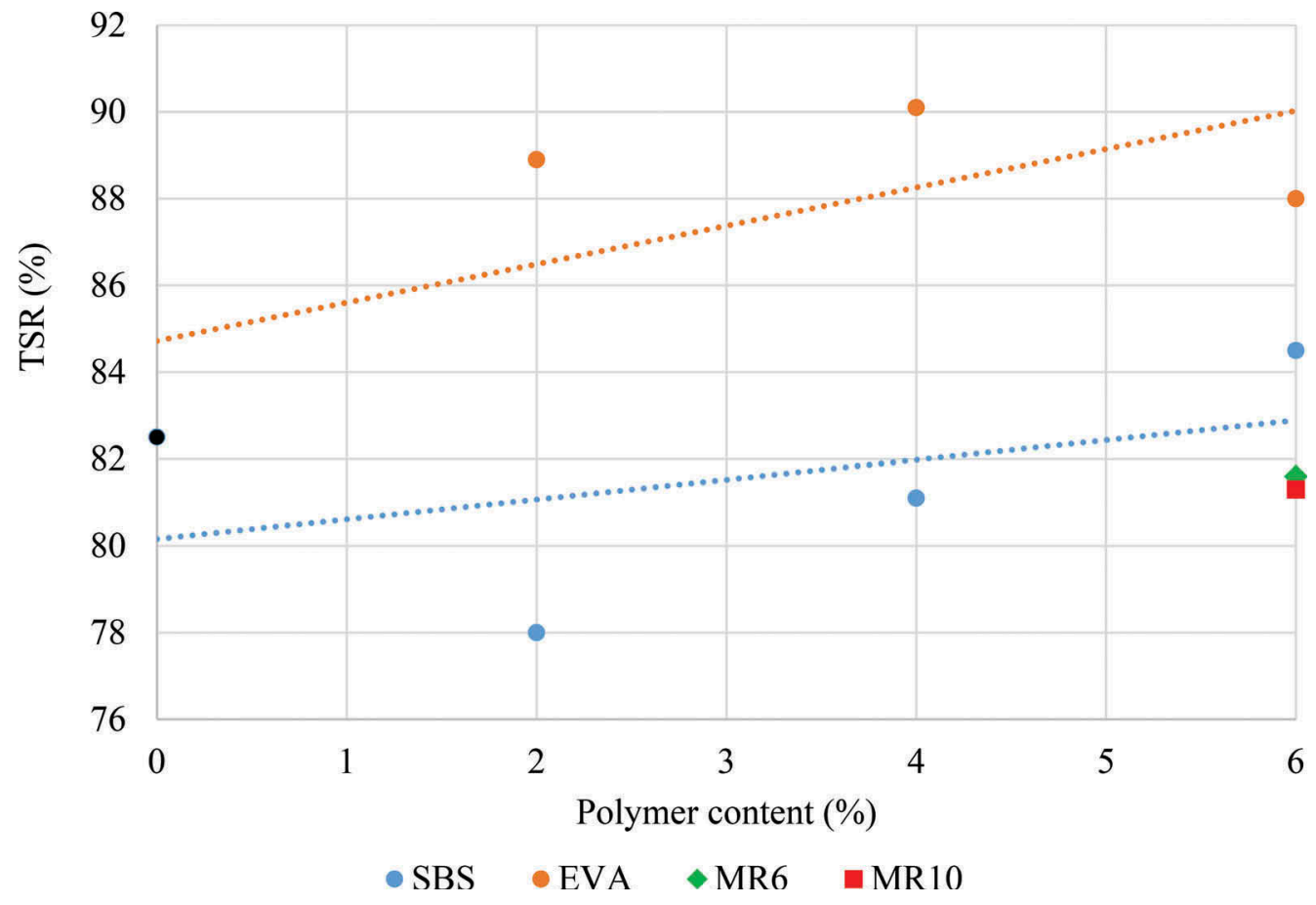

Figure 8. Asphalt mixture TSR.

\section{CONCLUSION}

Comparative performance-related testing of asphalt mixtures in the laboratory compared the effects of conventional elastomeric (SBS) and plastomeric (EVA) polymers, as well as MR6 and MR10 recycled plastic products, on the mechanical properties of a common dense graded asphalt mixture. It was found the recycled plastic, at a dosage of $6 \%$ of the bitumen mass, produced asphalt mixtures with comparable properties to conventional polymers. In particular, the Marshall stability associated with recycled plastic was comparable to that for $2-3 \%$ conventional polymer content, while indirect tensile stiffness and deformation resistance were comparable to $4-6 \%$ of conventional polymer. In contrast, workability, Marshall flow and moisture damage resistance were not significantly different for recycled plastic and conventional polymers, regardless of the conventional polymer content. It was concluded that the recycled plastic products used in this research should be thought of as sustainable polymers for asphalt mixture modification, rather than as extenders of the bituminous phase in asphalt production. However, further work is still required to understand the ageing of asphalt mixtures modified with recycled plastic, compared to unmodified bitumen and to conventional PMBs. The fuming and leaching potential of recycled plastic modification of asphalt must also be considered.

\section{REFERENCES}

Brasileiro, L., Moreno-Navarro, F., Tauste-Martinez, R., Matos, J. \& Rubio-Gamez, M. 2019, 'Reclaimed Polymers as Asphalt Binder Modifiers for More Sustainable Roads: A Review', Sustainability, vol. 11, pp. no. 646. 
Bousquin, J. 2020, 'California DOT repaves highway with recycled plastic bottles', Construction Dive, 26 August, accessed 23 September 2020, https://www.constructiondive.com/news/california-dotrepaves-highway-with-recycled-plastic-bottles/584131/.

BusinessTech, 2019, 'Works begins on South Africa's first Plastic Road', BusinessTech, 6 August, accessed 27 September 2020, https://businesstech.co.za/news/motoring/333307/work-begins-on-southafricas-first-plastic-road/

Dalhat, M. A. \& Wahhab, H. I., 2017, 'Performance of recycled plastic waste modified asphalt binder in Saudi Arabia', International Journal of Pavement Engineering, vol. 18, no. 4, pp. 349-357.

Doyle, S. 2019, 'Plastic road trials expanded by UK Government to stop potholes', Engineering \& Technology, 31 January, accessed 27 September 2020, https://eandt.theiet.org/content/articles/2019/01/plas tic-road-trials-expanded-by-uk-government-to-stop-potholes/.

Grifin, J. 2018, 'On the Road to Solving out Plastic Problem', UC San Diego News Center, 25 October, accessed 27 September 2020, https://ucsdnews.ucsd.edu/feature/on-the-road-to-solving-our-plasticproblem.

Houser, K 2019, 'Los Angeles is building a road from recycled plastic bottles', Futurism, 25 October, accessed 23 September 2020, https://futurism.com/the-byte/los-angeles-building-recycled-plastic-road.

IPWEA 2018, 'Soft plastics from about 200,000 plastic bags and packaging, and 63,000 glass bottle equivalents will be diverted from landfill to construct a Victorian road', Institute of Public Works Australasia, 29 May, accessed 7 April 2019, http://ipwea.org/blogs/intouch/2018/05/29/this-australian-firstroad-will-be-built-from-plas.

Jamieson, S. \& White, G. 2019, 'Improvements to the Australian wheel tracking protocol for asphalt deformation resistance measurement', Australian Geomechanics, vol. 54, no. 2, pp. 113-121.

Jamshidi, A. \& White, G. 2019, 'Use of recycled materials in pavement construction for environmental sustainability', Eighteenth Annual International Conference on Pavement Engineering, Asphalt Technology and Infrastructure, Liverpool, England, United Kingdom, 27-28 February.

Jamshidi, A. \& White, G. 2020, 'Evaluation of performance of challenges of use of waste materials in pavement construction: a critical review', Applied Sciences, vol. 10, no. 226, pp. 1-13.

MacRebur 2020, 'MacRebur Products', Lockerbie, Scotland, United Kingdom, accessed 7 April 2020, http://macrebur.com/pdfs/product/MacReburProductSheet_v1.pdf.

Masad, E., Roja, K. L., Rehman, A. \& Abdala, A. 2020, A Review of Asphalt Modification Using Plastics: A Focus on Polyethylene, Texas A\&M Univeristy, Qatar, Doha.

NAPA, 2019, Sustainable Asphalt Pavements: A Practical Guide, National Asphalt Pavement Association, Geenbelt, Maryland, United States of America, November 2019.

Nizamuddin, S., Jamal, M., Gravina, R. \& Giustozzi, F. 2020, 'Recycled plastic as bitumen modifier: the role of recycled linear low-density polyethylene in the modification of physical, chemical and rheological properties of bitumen', Journal of Cleaner Production, no. 266, pp. 1-12.

Parkes, R. 2018. 'Recycled plastic used in airport asphalt' Roads \& Infrastructure Australia, 5 April, accessed 7 April 2019, http://roadsonline.com.au/recycled-plastic-used-in-airport-asphalt/.

Pisani, A. 2018, 'SA's first recycled road made from binned plastic and glass', http://news.com.au, 11 December, accessed 7 April 2019, http://\%2522><www.news.com.au/national/south-australia/sas-firstrecycled-road-made-from-binned-plastic-and-glass/news-story/e7f03a9b43f797e651256d6bc8a4fc90>.

PTI 2015, 'Jamshedpur's Plastic Roads Initiative Is a Lesson for All Indian Cities!' India Times, accessed April 7, 2019, http://www.indiatimes.com/news/india/every-indian-city-needs-to-learn-from-juscos-plas tic-roads-in-jamshedpur-232246.html.

Ridden, P. 2012, 'The streets of Vancouver are paved with.... Recycled plastic', New Atlas, 1 December, accessed 7 April 2019, http://newatlas.com/vancouver-recycled-plastic-warm-mix-asphalt/25254/.

Roberts, L. 2019, 'Canberra roads to be paved with recycled plastic as Government trials new type of asphalt', Riotact!, 5 March, accessed 27 September 2020, https://the-riotact.com/canberra-roads-to-bepaved-with-recycled-plastic-as-government-trials-new-type-of-asphalt/289498.

Sani, S. 2015, 'Forget asphalt: a European city is building a road made entirely out of recycled plastic', Business Insider, 22 July, accessed 7 April 2019, https://www.businessinsider.com.au/a-dutch-city-isplanning-to-build-roads-from-recycled-plastic-2015-7? $r=U S \& I R=T$.

Tapsfield, J. 2018, 'Plastic and glass road that could help solve Australia's waste crisis', The Sydney Morning Herald, 2 August, accessed 7 April 2019, www.smh.com.au/environment/sustainability/plas tic-and-glass-road-that-could-help-solve-australia-s-waste-crisis-20180802-p4zv10.html.

White, G. 2019, 'Quantifying the impact of reclaimed asphalt pavement on airport asphalt surfaces', Construction and Building Materials, no. 197, pp. 757-765.

White, G. 2020, 'A Synthesis on the effects of two commercial recycled plastics on the properties of bitumen and asphalt', Sustainability, vol. 12, no. 8594, pp. 1-20. 
White, G. \& Hall, F. 2020, 'Comparing wet mixed and dry mixed binder modification with recycled waste plastic', RILEM International Symposium on Bituminous Materials, Lyon, France, 1416 December.

White, G. \& Hall, F. 2021, 'Laboratory Comparison of Wet-mixing and Dry-mixing of Recycled Waste Plastic for Binder and Asphalt Modification', $100^{\text {th }}$ TRB Annual Meeting: a virtual event, January.

White, G. \& Jamshidi, A. 2019, 'Resetting dense graded airport asphalt production and construction tolerances', International Journal of Construction Management, article-in-press.

White, G. \& Magee, C. 2019, 'Laboratory evaluation of asphalt containing recycled plastic as a bitumen extender and modifier', Journal of Traffic and Transportation Engineering, vol. 7, no. 5, pp. $218-235$.

White, G. \& Reid, G. 2018, 'Recycled waste plastic for extending and modifying asphalt binders', $8^{\text {th }}$ Symposium on Pavement Surface Characteristics (SURF 2018), Brisbane, Queensland, Australia, 2-4 April.

White, G. \& Reid, G. 2019, 'Recycled waste plastic modification of bituminous binder', $7^{\text {th }}$ International Conference on Bituminous Mixtures and Pavements, Thessaloniki, Greece, 12-14 June, pp. 3-12.

White, G. \& Reid, G. 2021, 'Recycled plastic as an alternate to conventional polymers for bituminous binder', $7^{\text {th }}$ Eurasphalt and Eurobitume Congress, Madrid, Spain, 16-18 June.

Yin, F., Moraes, R., Fortunatas, M., Tran, N. Elwardany, M.D. \& Planche, J.-P. 2020, Performance Evaluation and Chemical Characterization of Asphalt Binders and Mixtures Containing Recycled Polyethylene, Final Report, Plastic Industry Association, 10 March. 